\title{
Correction to: Adaptation of pine wood nematode, Bursaphelenchus xylophilus, early in its interaction with two Pinus species that differ in resistance
}

\author{
Yaqi Feng ${ }^{1,2} \cdot$ Lin Rui $^{1,2} \cdot$ Xinyu Wang ${ }^{1,2} \cdot$ Xiaoqin $\mathrm{Wu}^{1,2}$
}

Published online: 11 December 2021

(C) Northeast Forestry University 2021

\section{Correction to: J. For. Res.}

https://doi.org/10.1007/s11676-021-

01416-7

The corresponding author was incorrectly identified as Xinyu Wang during the production process. The corresponding author should be Xiaoqin Wu.

The original article has been corrected.

Publisher's Note Springer Nature remains neutral with regard to jurisdictional claims in published maps and institutional affiliations.

The original article can be found online at https://doi.org/10. 1007/s11676-021-01416-7.

Xiaoqin $\mathrm{Wu}$

xqwu@njfu.edu.cn; xqwu_njfu@163.com

1 Co-Innovation Center for Sustainable Forestry in Southern

China, College of Forestry, Nanjing Forestry University,

Nanjing 210037, People's Republic of China

2 Jiangsu Key Laboratory for Prevention and Management of Invasive Species, Nanjing Forestry University,

Nanjing 210037, People's Republic of China 